\title{
THE CLEANING OF SKELETONS BY MEANS OF LARVAE OF DERMESTID BEETLES by
}

\author{
A. D. J. MEEUSE
}

(Hugo de Vries Laboratory, University of Amsterdam ${ }^{*}$ )

\section{Introduction}

Skeletons are an essential part of every zoological collection. The cleaning of the carcasses or other crude skeletal material obtained from collected animals can be carried out by mechanical defleshing, by boiling in water with or without chemicals, or by a combination of mechanical cleaning and boiling, and these methods are employed in many musea as a routine treatment.

In the case of small specimens this process of scraping and boiling almost invariably destroys some of het more delicate structures, so that the preparators are usually very careful when handling small carcasses for fear of damaging them, which often results in incomplete cleaning in spite of their tedious and time-devouring work. They must often feel between the devil and the deep sea, because the obtained skeletons are either damaged or unsatisfactorily cleaned.

Dermestid beetles and their lar:ae normally feed on animal matter (hides, meat, fish, hair, horn, wool) and in nature frequently occur on carcasses, which they neatly deflesh, so that the suggestion to use them for cleaning skeletons is rather obvious. According to Hinton (1945) the first suggestion of this kind was made as early as 1876 (ANonYmous, 1876), but the method passed into oblivion and was only rediscovered in the early 'twenties (see TIEMEIER, 1940).

When the present author was first approached by Mr. (now Dr.) A. M. Husson, Curator of the Dept.

- Formerly, Dept. of Biological Technology, National Fibre Research Institute (Vezelinstituut T.N.O.), now incorporated in the Central Laboratory T.N.O. (Delft). The manuscript was completed several years ago, but for various reasons it was left lying. As it is thought that the topic has not lost its actuality, especially the "reconditioning" of old formalin-treated carcasses described in the text being of practical interest, it was decided to publish this paper. of Mammalogy of the Leyden Museum, with the request to develop a satisfactory biological method for cleaning small skeletons, it was because the Department of Biological Technology of the National Fibre Research Institute had gained a great deal of experience with the cultivation of Dermestids (Anthrenus, Anthrenocerus and Attagenus species). Our first experiments with larvae of Anthrenus vorax Waterh. and Dermestes lardarius L. were entirely unsuccessful. We doubt if VorHes's (1948) statement that in his "bug box" for cleaning skeletal material "Anthrenus varius" $\left[=A\right.$. verbasci $\left.\left(\mathrm{L}_{.}\right)\right]$is the predominating species, is correct, because we had negative results with $A$. vorax and because Hinton (1945) does not mention any record of an Anthrenus species as feeding on meat.

Attagenus piceus (Oliv.), mentioned by TIEMEIER (1940), was only tried by us later on, after we had obtained excellent results with Dermestes vulpinus F. which leave hardly any room for improvement.

As the existing literature on the subject (HaLl \& Russell, 1933; Borell, 1938; TIEMeier, 1940; RusSELL, 1947; VoRHIES, 1948; HOOPER, 1950) is rather contradictory as regards the species to be used and the best experimental conditions, and the various methods suggested are fairly complicated, we thought it worth while putting our experiences on record, the more so because we also experimented with very old and with spirit material, whereas the pertaining papers do not indicate if the existing methods can also be used for specimens that have been preserved in alcohol or formalin for some time. This point is very important for the Leyden Museum because all the material which cannot be treated at once is preserved in spirit. The material collected during the New Guinea Expedition to the Wissel Lakes in 1938 and during the Surinam Expedition of 1948/49, for instance, was completely preserved in alcohol. In addition, an extensive collection of Chiroptera has been kept in spirit since the end of the last century. It was, 
therefore, highly desirable to investigate the behaviour of Dermestes larvae towards alcohol material.

During a visit of Dr. T. C. S. Morrison-Scott, at the time Curator of Mammals of the Department of Zoology, British Museum (Natural History), he told Mr. Husson that Dermestid beetles were used at the British Museum according to data supplied by the Bureau of Animal Population, Oxford. Dr. MorrisonScott was so kind as to send some 30 specimens to Leyden with a detailed account by Miss E. M. $O$. Laurie of the method employed. The animals belong to the species Dermestes vulpinus F. $(=D$. maculatus Deg. according to Hinton, 1945). The instructions received from the British Museum were used as a starting point for our experiments, but were slightly modified. Other data, mentioned in the papers cited, have been verified. No essential changes in the existing methods have been made, but in our opinion, it is of the utmost importance that the method outlined in the present paper can also be used for old alcohol material, and, at least in several cases, for formalin material.

\section{Maintenance of the Dermestes cultures}

The original stock of Dermestes vulpinus consisted of the 30 specimens sent by the Department of Zoology, British Museum (Nat. Hist.). The animals are cultivated in jars. These rearing jars are prepared as follows: Glass containers (e.g., small aquaria, $20 \times 30 \times 20 \mathrm{~cm}$, or cylindric jars, 20 to $30 \mathrm{~cm}$ in diam.) are provided with a $1 \mathrm{~cm}$ layer of meat meal. Two teaspoonfuls of debittered brewers' yeast and one teaspoonful of cholesterol are sprinkled on to the surface of the meat meal. Yeast, i.e., certain vitamines, and cholesterol are essential for the successful development of the larvae (GAY, 1938).

A new culture is started by using fresh meat, because Russell (1947) has found that for maximum egg production a balanced diet consisting of fresh meat and fat is required. We also noticed a considerable decrease in the amount of young larvae and in the size of the adult beetles in our older cultures which had been used for skeleton cleaning and in which (apart from the meatmeal) old, dried carcasses were the only source of food. Cannibalism (in this case attack of pupae and of newly hatched beetles), which is also indicative of sub-optimal conditions, only occurs in old cultures and was never observed when fresh food was available.

Laboratory rats are easy to obtain and very good as a supply of fresh meat, but fresh carcasses of other animals, if not too fat or not too lean, are equally satisfactory. The fresh carcass is hung up and dried in the air for about 24 hrs. To start a colony, the two hindlegs of a rat (or an equivalent amount of food) are sufficient. Place the fresh meat on the meatmeal in the rearing jars, add 20 to 30 pupae or beetles and cover with several layers of cloth (sheet cotton, muslin, bunting etc.). The instructions received from the British Museum suggested "covering with a small handful of cotton wool". We found that pieces of cloth are far more satisfactory as will be discussed in the next paragraph. Cover the jar with a sheet of glass. Rear at $28^{\circ}-30^{\circ} \mathrm{C}$. $\left(82^{\circ}-86^{\circ} \mathrm{F}\right.$.), preferably in an incubator, but in any case in the dark. Avoid too much moisture: as soon as condensation of water vapour is noticed on the inside of the lid, remove the glass plate and leave the jar open for half an hour or so to let it dry. Too much moisture causes mould growth and is harmful to the larvae and especially to the pupae. If a rearing jar has become so moist that the meatmeal forms a hard wet mass, the only course of action is a complete removal of the living insects into a freshly prepared jar. Ventilation, on the other hand, is not necessary. Even if the lid fits tightly, the insects never seem to suffer from lack of air.

According to Russell (1947) the complete cycle is 45 days per generation at $85^{\circ} \mathrm{F}$. $\left(29.5^{\circ} \mathrm{C}\right.$.). The larvae enter their period of most active growth much sooner, so that a rearing jar is ready for skeleton cleaning three to four weeks after the new culture was started. A colony can be used for cleaning for not longer than two to three months, not so much because the activity of the larvae decreases as no fresh meat is supplied, but chiefly because the accumulation of larval skins and excrements renders the jar unsuitable. Such old cultures can be revived at any time by supplying fresh meat and a pinch of yeast, but this is not recommended. Large quantities of larval hairs of Dermestids may cause severe itching of the skin, irritation of the respiratory passages and other unpleasant effects (Lorr \& LEGANGNEUx, 1922; TIEMEIER, 1940), but we never suffered any complaints, presumably because the old colonies were discarded in time. By replacing two 3 to 4 months old cultures by fresh ones every month, the following rotation is obtained:

Two (3 to 4 months old) cultures are replaced by two fresh ones.

Two cultures ( 2 months old) are used for cleaning skeletons.

Two cultures ( 1 month old) are also used for skeleton cleaning.

Two fresh cultures replace the $3-4$ months old colonies (see above). 
By doing so four colonies are constantly available for skeleton cleaning.

\section{Skeleton cleaning}

We do not recommend the cleaning of carcasses of larger animals by means of Dermestes larvae, although the technique could easily be extended along the lines of the American system (by using large-scale "bug chests" and "bug rooms" instead of colonies in jars), because this would require a great deal of care and supervision for maintenance, temperature control, etc. Moreover, mechanical cleaning and boiling give quite satisfactory results with larger specimens in a rather short time, so that the biological method offers no advantages in this case, not even as a timesaving device.

For cleaning skeletal material of small and delicate species the biological method is far superior. Fresh carcasses and skulls (not older than a few weeks and only dried, not preserved in spirit) need not be pretreated. Old and dry material having been in the uncleaned state for a long time and specimens that have been preserved in spirit are cleaned much more rapidly after a soaking treatment in a suspension of yeast powder in a solution of meat extract: Add $10 \mathrm{~g}$ of debittered brewers' yeast to 1 . litre of hot water $\left(80^{\circ}-90^{\circ} \mathrm{C} .=175^{\circ}-190^{\circ} \mathrm{F}\right.$. $)$ under constant stirring. Stir again at intervals of about three minutes. After about 15 minutes add $30 \mathrm{ml}$ of a concentrated meat extract (Liebig's "Oxo" is excellent for the purpose; several other commercial products proved to be inferior in this respect, possibly because they are not made of real meat!). Stir till the extract is dissolved. Material preserved in alcohol must be thoroughly dried before the soaking treatment. Material preserved in formalin must also be thoroughly dried, but if the smell of formaldehyde is persistent, treat the carcasses with $1 / 4-1 / 2 \%$ hydrogen peroxide for a few hours, rinse in water and soak in the meat extractyeast suspension. The suspension can be used at once. Leave the specimens in it for $24 \mathrm{hrs}$. and dry them in the air until all superficial moisture has been removed. Adhering particles of yeast should not be wiped off. Before drying, the carcasses are sufficiently flexible to be "remodelled", if necessary, to fit into the rearing jars. Metal labels (copper or aluminium) are to be preferred, because they can be left attached to the specimens during the soaking and subsequent cleaning treatment. The meat extractyeast suspension can be used twice for soaking carcasses (on two consecutive days!) and is then discarded.

The soaked and dried skeletal material is placed in the rearing containers and a pinch of cholesterol is sprinkled on top of the specimens. (Cholesterol is soluble in alcohol and is therefore completely leached out of spirit material).

Delicate skeletal material (e.g. of bats) is carefully wrapped up in a piece of cheese cloth; larger specimens are placed on the meatmeal and covered with the fabric present in the jar. We found cotton wool unsatisfactory because delicate bones (e.g. ribs) become easily entangled and often break, so that we have discontinued using it. A skeleton neatly wrapped up in a piece of cloth does not suffer in this way and, in addition, not a single bone is lost. The hyoid bone for instance, even if completely detached, is always recovered. A round container, about $25 \mathrm{~cm}$ in diam., will hold 3 or 4 carcasses the size of a rat, or from 20 to 30 small skulls. More delicate skulls can be treated in separate containers (small glass jars or tubes) to which 20 to 30 small larvae are added.

After 3 to 7 days, depending on the size and the age of the colony, and the condition of the specimens, the material is satisfactorily cleaned as a rule. (Formalin material may take longer). The specimens are then transferred to a tray and all living larvae are removed. Tap skulls gently on the table to remove the larvae in the cranium and nasal passages. Clean the skeletons by dusting with a paint brush and by picking with fine tweezers.

We have treated material that had been preserved in alcohol for some 50 years and also very old, dry material in this way. The results were excellent, although as a rule the cleaning takes longer than the time required for fresh carcasses.

\section{Experiments with Attagenus piceus}

In order to verify TIEMEIER's (1940) statement that larvae of Attagenus piceus Oliv. are also excellent for cleaning skeletons, although they work much slowly, we exposed five carcasses of small mammals (mice, shrews) to about a thousand larvae of this species. These larvae were taken from our regular cultures and had been reared on woollen cloth (impregnated with yeast extract) to which a mixture of meatmeal (seven parts), maize meal (two parts) and yeast powder (one part) had been added. The carcasses were wrapped up in thin cotton cloth and placed in a glass jar covered with a piece of wire gauze. The jar was kept at $28^{\circ} \mathrm{C}$. and $60 \%$ R.H.

Attagenus larvae indeed work much more slowly than those of Dermestes, but the results are equally satisfactory. For cleaning very small and delicate skeletons they are probably superior to the larger 
Dermestes larvae. For very delicate and almost irreplaceable specimens, for instance, Attagenus piceus is a safer proposition than Dermestes vulpinus, but it would of course complicate matters considerably if cultures of both species have to be maintained. The alternative is the use of hand-picked very young Dermestes larvae in separate containers for cleaning small delicate specimens. We certainly do not recommend skeleton cleaning exclusively by means of cultures of Attagenus, because this would consume too much time. The other advantage mentioned by Tiemeier. viz. that Attagenus piceus larvae clean material refused by Dermestes, we found to be nonexistent in our case, because in all our experiments the Dermestes larvae did not refuse to clean a single carcass. This may be due to the soaking treatment in the meat extract-yeast suspension which we apply.

\section{After-treatment of the Carcasses}

As a rule skulls and skeletons are so well cleaned that they only need a treatment with a weak solution of hydrogen peroxide ( 1 to $3 \%$ ) for 6 to $12 \mathrm{hrs}$., if bleaching is desired. If they are not quite clean, or if they have to be degreased, the specimens are soaked in 5 to $10 \%$ ammonia for 3 to $6 \mathrm{hrs}$., rinsed in water and finally cleaned by gentle brushing with an old soft tooth brush in a stream of water under a tap. Either dry them at once, or first transfer them to hydrogen peroxide solution for bleaching.

\section{Time required for Cleaning}

The maintenance of the cultures requires not more than about 20 minutes a month, i.e., the time required for starting two new cultures.

With four colonies of Dermestes at full working strength an operator can clean (exclusive of bleaching etc.) from 80 to 100 skulls or from 12 to 20 skeletons of small mammals (rats, voles, moles, etc.) in a week for an expenditure of something like three hours of labour. HoOper (1950) mentions some data obtained at the Museum of Zoology, University of Michigan: for complete processing of 300 rodent skulls an operator required $1637 \mathrm{~min}$. or $5.45 \mathrm{~min}$. per skull, sometimes only about $3 \mathrm{~min}$. per skull. This agrees very well with our findings.

\section{Condition of the specimens}

When a skeleton is left in a rearing jar for a longer period than required for proper cleaning, no damage will occur to the specimen (compare Figure 1a, b, c). No bones are lost or destroyed by the activities of the larvae. We can fully endorse TIEMEIER's statements: “...the skeleton comes out intact with sutures in place and soft bones undissolved. No ligaments are weakened to the extent of loosing minute bones. Hyoid apparatus, zygomatics, lacrymals, auditory bullae, phalanges, and other elements are certain to be retained", and also HALL \& Russell's conclusions: "Processes are not broken off; delicate structures are not destroyed; teeth do not fall out; enough greasy material is left in the bones to prevent deterioration; and sutures do not gape even in young specimens". We cleaned many carcasses of Marsupials from New Guinea (see Fig. 2a, b), and we mention as a point of interest that almost invariably, and even in the smallest species, the epipubic or "marsupial" bones remain connected with the os pubis.

HOOPER (1950), who strongly advocates the use of Dermestid beetles instead of "cooking pots", mentions some interesting data showing the superiority of "bugged" over cooked and hand-cleaned skulls of Reithrodontomys. One lot of 42 hand-cleaned specimens contained only four entire skulls; one lot of 64 specimens cleaned by Dermestes larvae contained 59 complete and unbroken ones. His final remarks are certainly worth quoting, because they express our own ideas so perfectly: "It is urgently hoped that all research museums will adopt this modern method in the processing of skeletal materials. Why destroy good specimens?"

\section{LITERATURE CITED}

ANonymous, 1876: (No title.) Feuill. jeun. Nat. Vol. 6, p. 90.

Borel, A. E., 1938: Cleaning Small Collections of Skulls with Dermestid Beetles. J. Mammal., Vol. 19, pp. 102103.

GAY, F. J., 1938: A Nutritional Study of the Larva of
Dermestes vulpinus F. J. Exp. Zool., Vol. 79, pp. 93107.

Hall, E. R. and Russell, W. C., 1933: Dermestes Beetles as an Aid in Cleaning Bones. J. Mammal., Vol. 14, pp. 372-374.

Hinton, H. E., 1945: A Monograph of the Beetles Asso- 

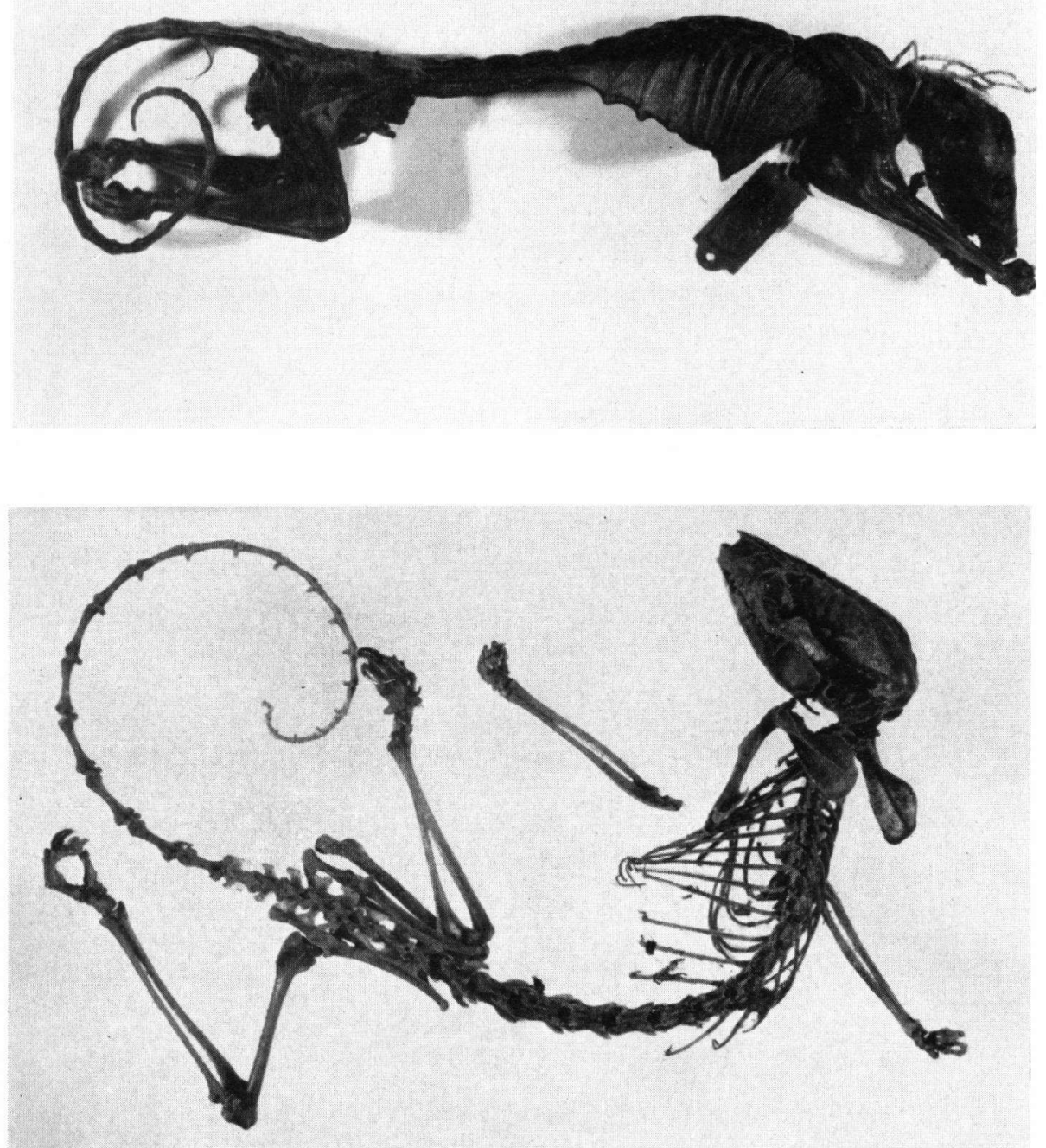

Fig. 2. a. Carcass of a rat-like marsupial from New Guinea, which had been preserved in formalin for a number of years, $\times 1 / 2$. $b$. The same carcass, after 'reconditioning' and cleaning by Dermestes larvae, $\times 2 / 3$. Note thoroughness of defleshing and condition of costae and tail vertebrae. 


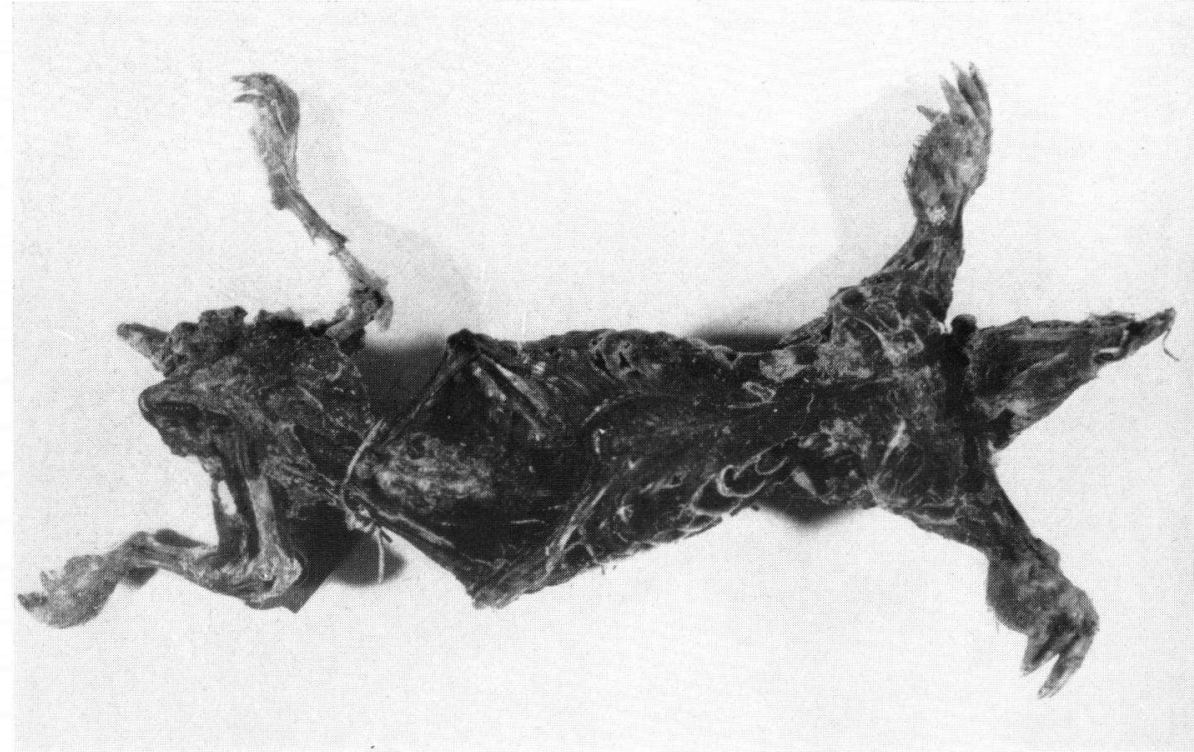

$b$

Fig. 1. a. Carcass of a mole, initial stage of defleshing by larvae of Dermestes vulpinus.

b. The same carcass, after cleaning by Dermestes larvae.

c. The same skeleton as shown in Fig. $1 b$, after bleaching and mounting.

Note condition of costae. (All figures natural size.)

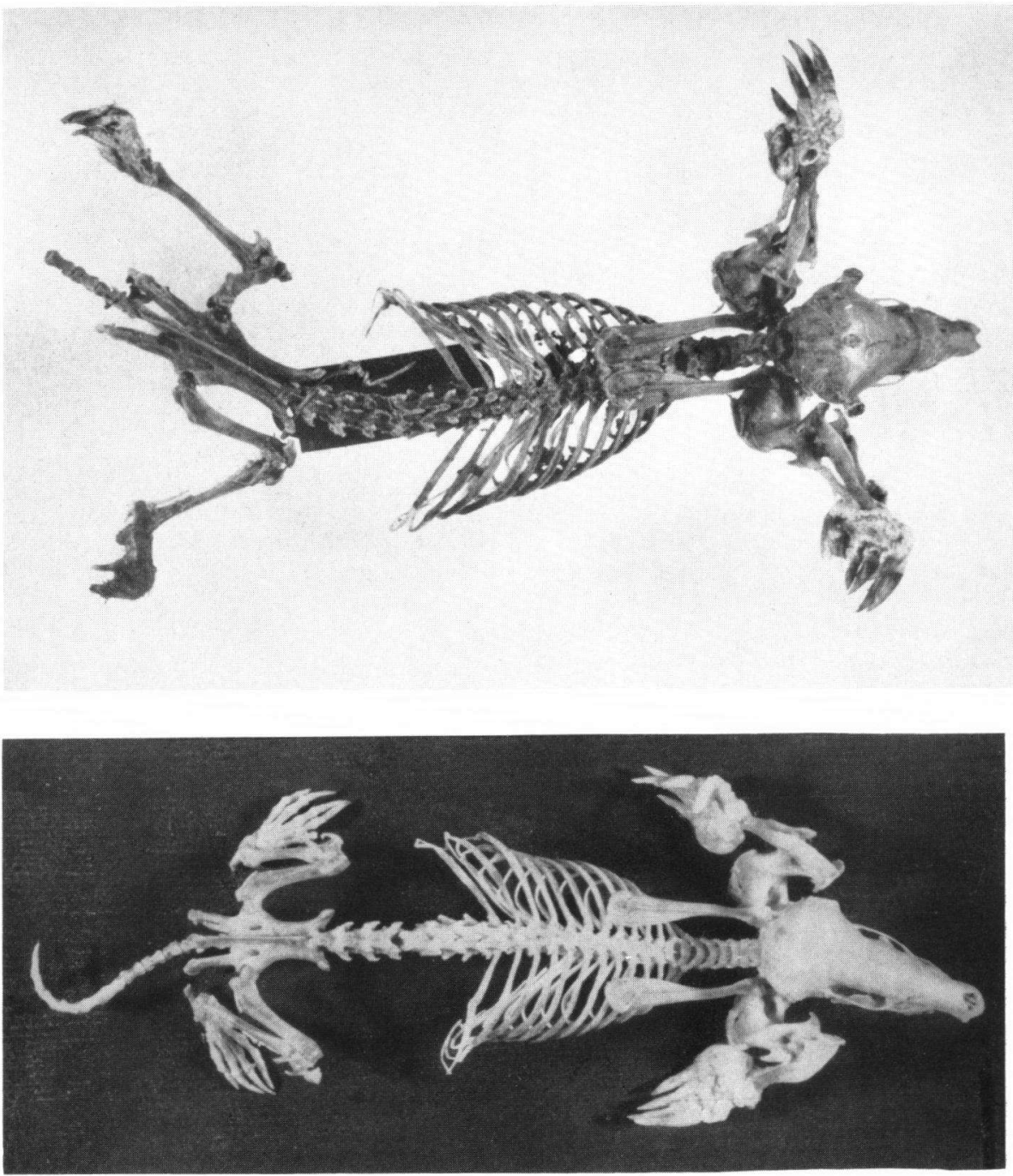


ciated with Stored Products. Vol. 1 (Dermestidae on p. 234 et seq.) London - British Museum (Nat. Hist.). HOOPER, E. T., 1950: Use Dermestid Beetles Instead of Cooking Pots. J. Mammal., Vol. 31, pp. 100-102.

LoIR, A. and H. Legangneux, 1922: Accidents de travail occasionnés par des coléoptères. Bull. Acad. Méd. Paris., Vol. 88, pp. 68-72.
Russell, W. C., 1947: Biology of the Dermestid Beetle with Reference to Skull Cleaning. J. Mammal., Vol. 28, pp. 284-287.

TIEMEIER, O. W., 1940: The Dermestid Method of Cleaning Skeletons. Univ. Kansas Sci. Bull., Vol. 26, No. 10, pp. 377-383.

VorHIES, C. T., 1948: A Chest for Dermestid Cleaning of Skulls. J. Mammal., Vol. 29, pp. 188-189. 